\begin{tabular}{ccc}
$\begin{array}{c}\text { Transcription } \\
\text { factor }\end{array}$ & Role in the growth plate & Reference \\
\hline Mef2c & & {$[69]$} \\
Tcf7 & Promotes hypertrophy & {$[70]$} \\
Dlx5 & & {$[41]$} \\
Msx2 & Inhibits hypertrophy & {$[40]$} \\
\hline Foxp1 & & {$[71]$} \\
\hline Hey1 & Inhibits terminal differentiation or & {$[39]$} \\
Sox9 & cartilage resorption & {$[41]$} \\
Dlx5 & & {$[40]$} \\
Msx2 & Promotes terminal differentiation & {$[72]$} \\
\hline Rbpj & or cartilage resorption & \\
\hline
\end{tabular}

\title{
Additional References
}

69. Arnold MA, Kim Y, Czubryt MP, Phan D, McAnally J, et al. (2007) MEF2C transcription factor controls chondrocyte hypertrophy and bone development. Dev Cell 12: 377-389. doi:10.1016/j.devcel.2007.02.004.

70. Mikasa M, Rokutanda S, Komori H, Ito K, Tsang YS, et al. (2010) Regulation of Tcf7 by Runx2 in chondrocyte maturation and proliferation. Journal of Bone and Mineral Metabolism 29: 291-299. doi:10.1007/s00774-010-0222-z.

71. Guo X, Zhao H (2012) Foxp1/2/4, New Transcriptional Regulators for the Chondrocyte Hypertrophy and Osteoblast Differentiation during Skeletal Ossification Minneapolis.

72. Kohn A, Dong Y, Mirando AJ, Jesse AM, Honjo T, et al. (2012) Cartilage-specific RBPj -dependent and -independent Notch signals regulate cartilage and bone development. Development 139: 11981212. doi:10.1242/dev.070649. 